\title{
The implications of intradural extension in paraspinal malignant peripheral nerve sheath tumors: effects on central nervous system metastases and overall survival
}

\author{
Hannah E. Gilder, MD, Ross C. Puffer, MD, Mohamad Bydon, MD, and Robert J. Spinner, MD \\ Department of Neurosurgery, Mayo Clinic, Rochester, Minnesota
}

OBJECTIVE In this study, the authors sought to compare tumors with intradural extension to those remaining in the epidural or paraspinal space with the hypothesis that intradural extension may be a mechanism for seeding of the CSF with malignant cells, thereby resulting in higher rates of CNS metastases and shorter overall survival.

METHODS The authors searched the medical record for cases of malignant peripheral nerve sheath tumors (MPNSTs) identified from 1994 to 2017. The charts of the identified patients were then reviewed for tumor location to identify patients with paraspinal malignancy. All patients included in the study had tumor specimens that were reviewed in the surgical pathology department. Paraspinal tumors with intradural extension were identified in the lumbar, sacral, and spinal accessory nerves, and attempts were made to match this cohort to another cohort of patients who had paraspinal tumors of the cranial nerves and lumbar and sacral spinal regions without intradural extension. Further information was collected on all patients with and without intradural extension, including date of diagnosis by pathology specimen review; nerve or nerves of tumor origin; presence, location, and diagnostic date of any CNS metastases; and either the date of death or date of last follow-up.

RESULTS The authors identified 6 of 179 (3.4\%) patients who had intradural tumor extension and compared these patients with 12 patients who harbored paraspinal tumors that did not have intradural extension. All tumors were diagnosed as high-grade MPNSTs according to the surgical pathology findings. Four of $6(66.7 \%)$ patients with intradural extension had documented CNS metastases. The presence of CNS metastases was significantly higher in the intradural group than in the paraspinal group (intradural, $66.7 \%$ vs paraspinal, $0 \% ; p<0.01$ ). Time from diagnosis until death was 11.2 months in the intradural group and approximately 72 months in the paraspinal, extradural cohort.

CONCLUSIONS In patients with intradural extension of paraspinal MPNSTs, significantly higher rates of CNS metastases are seen with a reduced interval of time from diagnosis to metastatic lesion detection. Intradural tumor extension is also a poor prognostic factor for survival, with these patients showing a reduced mean time from diagnosis to death.

https://thejns.org/doi/abs/10.3171/2018.5.SPINE18445

KEYWORDS MPNST; intradural; extension; paraspinal; survival; metastases; oncology

$\mathrm{M}$ ALIGNANT peripheral nerve sheath tumors (MPNSTs) are rare neoplasms accounting for less than $10 \%$ of all soft tissue sarcomas with an overall incidence of $0.001 \%$ in the general population. ${ }^{4}$ They may arise sporadically, in association with neurofibromatosis type 1 (approximately 50\% of cases), or as a secondary malignancy in the decades after radiation treatment (approximately 10\% of cases)., ${ }^{3,7}$ While these neoplasms may arise from any peripheral nerve in the body, nearly half originate in the extremities, with approximately $20 \%$ occurring in the head and neck, and the remainder being found in the trunk. ${ }^{11}$ The location of MPNST origin is a factor when predicting disease-specific survival (DSS), with the head and neck location associated with higher 5-year DSS, and the truncal location previously identified as a poor prognostic indicator. ${ }^{6,11}$ Standard screening for metastatic disease usually includes chest imaging for pulmonary lesions, although distant metastases, including to the brain, have been reported in the literature. ${ }^{9}$

Truncal location has been identified as a poor prognostic indicator and, more specifically, spinal tumors have been theorized to have a greater potential for brain metastases.

ABBREVIATIONS DSS = disease-specific survival; MPNST = malignant peripheral nerve sheath tumor .

SUBMITTED April 10, 2018. ACCEPTED May 22, 2018.

INCLUDE WHEN CITING Published online September 21, 2018; DOI: 10.3171/2018.5.SPINE18445. 
Nonetheless, no published literature to date has shown a potential mechanism for these hypotheses, although CSF is the hypothesized route for malignant dissemination. ${ }^{9} \mathrm{In}$ this study, we sought to compare tumors with intradural extension to those remaining in the epidural or paraspinal space with the hypothesis that intradural extension may be a mechanism for seeding of the CSF with malignant cells, thereby resulting in higher rates of CNS metastases and shorter overall survival.

\section{Methods}

This study underwent review and approval by our institutional review board. We searched the medical record for cases of MPNSTs identified from 1994 to 2017. The charts of the identified patients were then reviewed for tumor location to identify patients with paraspinal malignancy. Any patient without tumor location documented by a provider at our institution was excluded from the study. Paraspinal location was defined as an MPNST arising from, or with significant extension along, a spinal nerve.

Within the cohort of patients with paraspinal MPNSTs, radiology and operative reports were reviewed to identify tumors with intradural spread. For the purposes of this study, intradural spread was established either by a radiology report identifying a tumor involving a spinal nerve with contiguous spread of the mass through the epidural space and into the thecal sac or by an operative report in which the surgeon described that, in an attempt to resect the mass, the tumor had been dissected away from the dura. Tumor specimens obtained in all study patients were reviewed by our surgical pathology department, and any patient receiving a diagnosis at another hospital and who did not undergo further tissue review or biopsy at our institution was excluded from the study.

Paraspinal tumors with intradural extension were identified in the lumbar, sacral, and spinal accessory nerves, and attempts were made to match this cohort with another cohort of patients who had paraspinal tumors of the cranial nerves and lumbar and sacral spinal regions without intradural extension. Adjuvant treatment varied among the cohort depending on tumor location, treatment history, and patient factors, but it often included preoperative radiation therapy and doxorubicin-based chemotherapy regimens. Further information was collected for all patients with and without intradural extension, including date of diagnosis by pathology specimen review; nerve or nerves of tumor origin; presence, location, and diagnostic date of any CNS metastases; and either the date of death or date of last follow-up. This information was then analyzed and compared between groups to reflect rates of CNS metastases via chi-square test analysis, time from diagnosis to distant metastatic disease, and time from diagnosis to death. Commercially available software (JMP, SAS Institute) was used for statistical calculations and chart generation, and $\mathrm{p} \leq 0.05$ was considered significant.

\section{Results}

We identified 6 of 179 (3.4\%) patients who had intradural tumor extension (Fig. 1A). All tumors were diagnosed as high-grade MPNSTs by the surgical pathology depart-
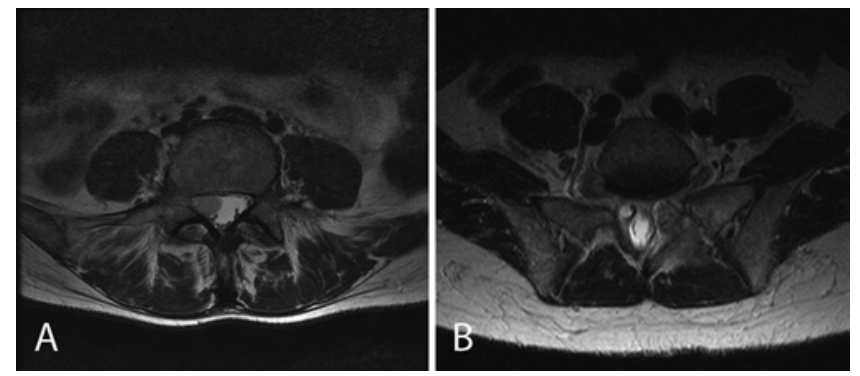

FIG. 1. A: Axial T2-weighted MR image of the lumbar spine in a patient with a right L5 MPNST. The tumor mass is apparent within the CSF space, suggesting intradural invasion. B: Axial T2-weighted MR image obtained in a patient with a left S1 MPNST in the epidural and paraspinal space without intradural extension.

ment, and 3 of $6(50 \%)$ patients had received regional radiation therapy for another condition prior to the diagnosis of the MPNST. Five of the MPNSTs were in the lumbosacral region; in the remaining patient, a mass was found along the spinal accessory nerve with extension through the jugular foramen, descending intradurally within the lower cranial nerve complex (Table 1). Four (66.7\%) of the patients with intradural extension had documented CNS metastases. In the patients with metastatic disease, $3 \mathrm{had}$ lesions discovered within the spine and 1 was diagnosed with brain metastases. The presence of CNS metastases was significantly higher in the intradural group than in the paraspinal group (intradural, $66.7 \%$ vs paraspinal, $0 \% ; \mathrm{p}<0.01)$. The time from diagnosis of the intradural MPNST until discovery of CNS metastases ranged from 3 to 6 months with a mean of 4.25 months (SD 1.3 months). Time from diagnosis until death ranged from 3 to 22 months, with a mean of 11.2 months (SD 9.5), excluding one patient who was lost to follow-up.

Twelve patients were identified as comparison patients with lumbar or sacral spinal nerve high-grade MPNSTs that did not enter into the intradural space (Fig. 1B and Table 2); one of these patients (8\%) had a history of prior regional radiation therapy. In this cohort of patients, none were identified with metastatic disease to the brain or spine. Nine patients had died, and 3 were alive at final follow-up. Of the patients who died, the average time from MPNST diagnosis to death was approximately 72 months. Two patients survived longer than 60 months, making the 5 -year survival rate $17 \%$. Yearly Kaplan-Meier survival probability estimates up to 5 years after diagnosis are shown for both groups with and without intradural extension in Table 3. Kaplan-Meier survival curves for each group are demonstrated in Fig. 2.

\section{Discussion}

Patients who harbor an MPNST that crosses from the extradural to intradural space have a significantly higher risk of CNS metastases as well as a substantially shorter life expectancy (11 months vs 72 months) in this series. It is likely that once the tumor has breached the dura, cells are free to metastasize via either CSF circulation or direct progression along the epineurium and/or leptomeninges of 
TABLE 1. Paraspinal MPNSTs with intradural extension

\begin{tabular}{|c|c|c|c|c|c|c|}
\hline $\begin{array}{l}\text { Case } \\
\text { No. }\end{array}$ & $\begin{array}{l}\text { Age } \\
\text { (yrs), } \\
\text { Sex }\end{array}$ & Nerve of Origin & Type of Surgery & $\begin{array}{l}\text { CNS } \\
\text { Metastases }\end{array}$ & $\begin{array}{c}\text { Time From Intradural } \\
\text { MPNST Dx to CNS } \\
\text { Metastases (Mos) }\end{array}$ & $\begin{array}{c}\text { Time From } \\
\text { Intradural MPNST } \\
\text { Dx to Death (Mos) }\end{array}$ \\
\hline 1 & $36, \mathrm{M}$ & S1 & $\begin{array}{l}\text { Initial: extradural complete resection; subsequent: } \\
\text { intradural exploration \& resection after recurrence }\end{array}$ & $\begin{array}{l}\text { Spine (thoracic/ } \\
\text { lumbar) }\end{array}$ & 6 & $10 \dagger$ \\
\hline 2 & $43, \mathrm{~F}$ & L5 & Combined intradural/extradural resection & Brain (diffuse) & 3 & 4 \\
\hline $3^{*}$ & $60, \mathrm{~F}$ & S2 & CT-guided biopsy & None & NA & 3 \\
\hline 4 & $32, F$ & L3 & $\begin{array}{l}\text { L3 nerve root completely resected; positive proximal } \\
\text { margins \& intradural resection was not performed }\end{array}$ & Spine (diffuse) & 4 & 21 \\
\hline 5 & $35, \mathrm{~F}$ & L5 & Combined intradural/extradural resection & None & NA & 22 \\
\hline 6 & $33, \mathrm{M}$ & Spinal accessory & Combined intradural/extradural resection & Spine (diffuse) & 4 & 6 \\
\hline
\end{tabular}

$\mathrm{Dx}=$ diagnosis; $\mathrm{NA}=$ not applicable.

* Diagnosis of neurofibromatosis type 1 .

† This patient was lost to follow-up. The duration listed represents the time he was last known to be alive.

the cauda equina to the spinal cord itself. ${ }^{9}$ These findings are important to consider when developing a treatment plan for a patient with a paraspinal, intradural MPNST.

CNS metastases are demonstrated not only in cases of intradural tumor location; brain metastases have been reported to have occurred from extremity MPNSTs, indicating that hematogenous spread of tumor cells cannot be excluded as a mechanism, although perhaps one that is much rarer and less facilitative of spread to the CNS than an intradural location. ${ }^{8}$ Three of the 4 patients with CNS metastases had negative CSF sampling findings for malignant cells via lumbar puncture, so CSF sampling for diagnostic purposes may not provide accurate results regarding the presence or absence of CNS metastases.

In previous literature that reviewed MPNSTs with metastases to the brain, the average time from tumor diagnosis to brain lesion detection was 41 months..$^{89}$ There has been one reported case of an intradural MPNST with metastatic lesions to the leptomeninges of the spine and brain that occurred 19 months after diagnosis. ${ }^{10}$ In our cohort of patients with intradural extension and CNS metastases, the average interval from diagnosis to metastatic lesion detection in the brain or spine was 4.25 months, a much shorter time frame than that previously reported for MPNST metastases to the CNS.

Although primary management for MPNSTs is en bloc resection with wide margins, in cases of paraspinal location, this becomes increasingly difficult without causing severe morbidity. An inability to achieve tumor-free margins is a recognized poor prognostic factor for survival in MPNST patients in general. ${ }^{1,2}$ In the case of paraspinal MPNSTs, resecting the tumor adjacent to-and therefore most likely to breach - the dura may be especially important in order to avoid intradural extension and subsequent metastases. In cases of confirmed intradural extension, surgical decision-making may shift from en bloc excision with wide margins to decompression of symptomatic neural elements and removal of gross disease that can be safely accessed and resected without increasing postoperative morbidity.

TABLE 2. Paraspinal MPNSTs without intradural extension

\begin{tabular}{ccclc}
\hline Case No. & Age (yrs), Sex & Nerve of Origin & \multicolumn{1}{c}{ Type of Surgery } & Time From MPNST Dx to Death (mos) \\
\hline 7 & $57, \mathrm{M}$ & L5 & Hemipelvectomy/complete resection & 17 \\
\hline 8 & $23, \mathrm{M}$ & $\mathrm{L} 4-5$ & Complete resection & 480 \\
\hline $9^{*}$ & $26, \mathrm{~F}$ & $\mathrm{~S} 1$ & Hemipelvectomy/complete resection & 10 \\
\hline 10 & $63, \mathrm{M}$ & $\mathrm{L} 3-4-5$ & Complete resection & 30 \\
\hline $11^{*}$ & $35, \mathrm{M}$ & $\mathrm{S} 2$ & Hemipelvectomy/complete resection & $131 \dagger$ \\
\hline $12^{*}$ & $43, \mathrm{~F}$ & $\mathrm{~L} 5-\mathrm{S} 1$ & Complete resection & 25 \\
\hline 13 & $43, \mathrm{M}$ & $\mathrm{S} 2-3$ & Sacrectomy/complete resection & 56 \\
\hline 14 & $21, \mathrm{M}$ & $\mathrm{S} 2-3$ & Complete resection & 10 \\
\hline $15^{*}$ & $31, \mathrm{~F}$ & $\mathrm{~S} 2-3$ & Sacrectomy/complete resection & 19 \\
\hline $16^{*}$ & $51, \mathrm{M}$ & $\mathrm{L} 5-\mathrm{S} 1$ & Biopsy & 22 \\
\hline 17 & $40, \mathrm{M}$ & S1 & Hemisacrectomy/complete resection & $42 \dagger$ \\
\hline 18 & $67, \mathrm{M}$ & S2-3 & Hemisacrectomy/complete resection & $22 \dagger$ \\
\hline
\end{tabular}

* Diagnosis of neurofibromatosis type 1 .

$\dagger$ These patients were alive at the most recent follow-up. The duration listed is the time they were last noted to be alive. 
TABLE 3. Kaplan-Meier survival probability estimates

\begin{tabular}{|c|c|c|c|c|c|c|}
\hline & \multicolumn{3}{|c|}{$\begin{array}{c}\text { Paraspinal w/ Intradural } \\
\text { Extension }\end{array}$} & \multicolumn{3}{|c|}{$\begin{array}{c}\text { Paraspinal w/o Intradural } \\
\text { Extension }\end{array}$} \\
\hline & \multirow{2}{*}{$\begin{array}{c}\text { Survival } \\
\text { Probability } \\
\text { Estimate }\end{array}$} & \multicolumn{2}{|c|}{$95 \% \mathrm{Cl}$} & \multirow{2}{*}{$\begin{array}{c}\text { Survival } \\
\text { Probability } \\
\text { Estimate }\end{array}$} & \multicolumn{2}{|c|}{$95 \% \mathrm{Cl}$} \\
\hline & & $\begin{array}{l}\text { Lower } \\
\text { Limit }\end{array}$ & $\begin{array}{l}\text { Upper } \\
\text { Limit }\end{array}$ & & $\begin{array}{l}\text { Lower } \\
\text { Limit }\end{array}$ & $\begin{array}{l}\text { Upper } \\
\text { Limit }\end{array}$ \\
\hline Year 1 & 0.5 & 0.14 & 0.86 & 0.85 & 0.54 & 0.97 \\
\hline Year 2 & 0 & 0 & 0.48 & 0.62 & 0.32 & 0.85 \\
\hline Year 3 & & & & 0.44 & 0.19 & 0.72 \\
\hline Year 4 & & & & 0.44 & 0.19 & 0.72 \\
\hline Year 5 & & & & 0.33 & 0.12 & 0.63 \\
\hline
\end{tabular}

Previous large studies of MPNSTs have yielded 5-year DSS rates of $46 \%-60 \%$, with the mean patient survival time (measured in patients who died of their illness) reported as 25 months. ${ }^{4,5,11}$ In our study, the mean survival time was 11.2 months in patients in the intradural cohort and approximately 72 months in patients in the comparison group. Patients in our series with intradural tumor extension therefore have a survival time less than half of what has previously been reported for overall MPNST cases. Although patients with paraspinal tumors without intradural extension had a mean survival time over 6 times that of those with tumors crossing the dura, in this particular comparison group, the 5-year survival rate was only $17 \%$, approximately one-half to one-third of the rate reported in the literature for overall MPNST cases in any location. No patient in this series with intradural extension survived 2 years after diagnosis.

\section{Conclusions}

In patients with intradural extension of paraspinal MPNSTs, significantly higher rates of CNS metastases are seen with a reduced interval of time from diagnosis to metastatic lesion detection. Intradural tumor extension

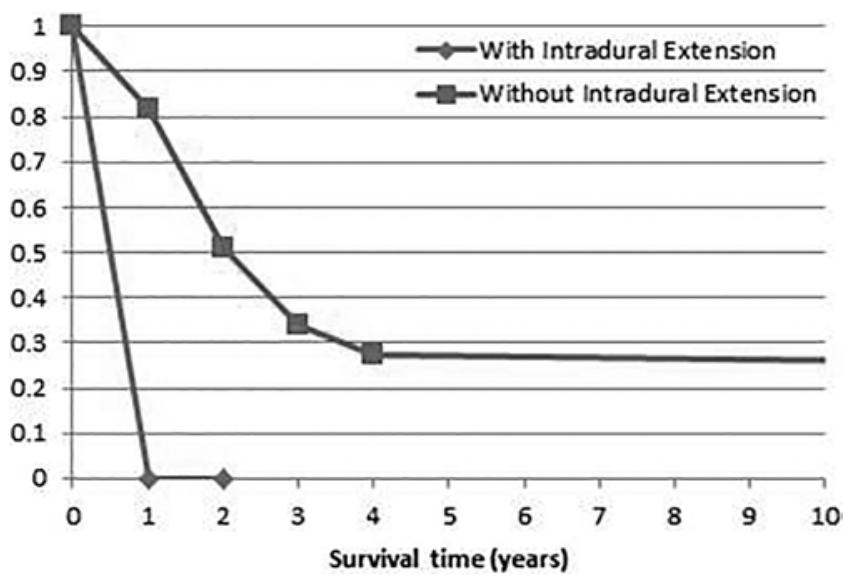

FIG. 2. Kaplan-Meier survival curves for patients with paraspinal MPNSTs with and without intradural extension. is also a poor prognostic factor for survival, with these patients showing a reduced mean time from diagnosis to death.

\section{References}

1. Amirian ES, Goodman JC, New P, Scheurer ME: Pediatric and adult malignant peripheral nerve sheath tumors: an analysis of data from the surveillance, epidemiology, and end results program. J Neurooncol 116:609-616, 2014

2. Baehring JM, Betensky RA, Batchelor TT: Malignant peripheral nerve sheath tumor: the clinical spectrum and outcome of treatment. Neurology 61:696-698, 2003

3. Ducatman BS, Scheithauer BW, Piepgras DG, Reiman HM, Ilstrup DM: Malignant peripheral nerve sheath tumors. A clinicopathologic study of 120 cases. Cancer 57:2006-2021, 1986

4. Kim DH, Murovic JA, Tiel RL, Moes G, Kline DG: A series of 397 peripheral neural sheath tumors: 30 -year experience at Louisiana State University Health Sciences Center. J Neurosurg 102:246-255, 2005

5. Kolberg M, Høland M, Agesen TH, Brekke HR, Liest $\varnothing 1$ K, Hall KS, et al: Survival meta-analyses for $>1800$ malignant peripheral nerve sheath tumor patients with and without neurofibromatosis type 1. Neuro Oncol 15:135-147, 2013

6. Patel TD, Shaigany K, Fang CH, Park RC, Baredes S, Eloy JA: Comparative analysis of head and neck and non-head and neck malignant peripheral nerve sheath tumors. Otolaryngol Head Neck Surg 154:113-120, 2016

7. Perrin RG, Guha A: Malignant peripheral nerve sheath tumors. Neurosurg Clin N Am 15:203-216, 2004

8. Puffer RC, Graffeo CS, Mallory GW, Jentoft ME, Spinner RJ: Brain metastasis from malignant peripheral nerve sheath tumors. World Neurosurg 92:580.e1-580.e4, 2016

9. Shweikeh F, Bukavina L, Saeed K, Sarkis R, Suneja A, Sweiss F, et al: Brain metastasis in bone and soft tissue cancers: a review of incidence, interventions, and outcomes. Sarcoma 2014:475175, 2014

10. Stark AM, Mehdorn HM: Leptomeningeal metastasis of an intradural malignant peripheral nerve sheath tumor. J Clin Neurosci 20:1181-1183, 2013

11. Stucky CC, Johnson KN, Gray RJ, Pockaj BA, Ocal IT, Rose PS, et al: Malignant peripheral nerve sheath tumors (MPNST): the Mayo Clinic experience. Ann Surg Oncol 19:878-885, 2012

\section{Disclosures}

The authors report no conflict of interest concerning the materials or methods used in this study or the findings specified in this paper.

\section{Author Contributions}

Conception and design: Spinner, Puffer. Acquisition of data: Puffer. Analysis and interpretation of data: Gilder, Puffer, Bydon. Drafting the article: Gilder, Puffer. Critically revising the article: Spinner, Puffer. Reviewed submitted version of manuscript: Spinner, Puffer. Approved the final version of the manuscript on behalf of all authors: Spinner. Statistical analysis: Puffer. Administrative/technical/material support: Spinner, Bydon. Study supervision: Spinner, Bydon.

\section{Correspondence}

Robert J. Spinner: Mayo Clinic, Rochester, MN. spinner.robert@ mayo.edu. 